\title{
Christmas Tree Sign: Paraspinal Cerebrospinal Leak on 99mtc-DTPA Radionuclide Cisternography
}

Nosheen Fatima ${ }^{1}$, Maseeh uz Zaman ${ }^{2 *}$, Atta ul Aleem Bhatti ${ }^{3}$, Imtiazul Haque Khurshaidi ${ }^{1}$, Ali Jawaid Siddiqui ${ }^{1}$ and Aitadal Moin Shaikh ${ }^{1}$

${ }^{1}$ Department of Nuclear Medicine, Dr. Ziauddin Medical University Hospital, Karachi, Pakistan

${ }^{2}$ Nuclear Medicine Section, Department of Radiology, Aga Khan University Hospital, Karachi, Pakistan

${ }^{3}$ Departmentof Neurosurgery, Dr. Ziauddin Medical University Hospital, Karachi, Pakistan

\begin{abstract}
Radionuclide cisternography $(\mathrm{RC})$ is an underutilized but sensitive modality used to differentiate between normal pressure and non-communicating hydrocephalus and can also detect cerebrospinal fluid (CSF) leakage. We present a case of intracranial tuberculous with severe headache and hydrocephalus. RC was performed with Tc-99m labeled DTPA showing communicating hydrocephalus with characteristics Christmas tree sign and early appearance of renal activity due to spinal CSF leak into systemic circulation. This patient responded well to ventriculo-peritoneal shunt (VP shunt).
\end{abstract}

Keywords: Radionuclide cisternography; Tc-99m DTPA; Cerebrospinal fluid leakage; Hydrocephalus; Christmas tree

\section{Case Report}

A 50 years old male of average built and height presented with 2 months history of sudden onset of severe fronto-occiptal headache. Intensity of pain was used to aggravate in upright position. Past history was unremarkable. Physical examination revealed no neurological deficit. Pre-admission head CT revealed dilated ventricles with pervientricular ischemic changes. A lumbar puncture was performed at L3/4 level under aseptic measures with an opening pressure of 32 $\mathrm{cmH}_{2} \mathrm{O}$ with a clear and colorless fluid. CSF analysis revealed protein concentration of $53 \mathrm{mg} / \mathrm{dl}(20-40 \mathrm{mg} / \mathrm{dl})$, glucose level $43 \mathrm{mg} / \mathrm{dl}$ (40-80 mg/dl), WBC 16/cumm (0-5), Neutophils 03\%, Lymphocytes $40 \%$, Monocytes $7 \%$ and no evidence of abnormal cell or bacteria in culture and on PCR. Radionuclide cisternography was performed by administrating $185 \mathrm{MBq}$ of Tc- ${ }^{99 \mathrm{~m}}$ DTPA intrathecally. Sequential static images of spine and head both in posterior and lateral views were obtained at 1 hour, 2 hour and 18 hour after injection. Scans showed appearance of tracer in the spinal subarachnoid space with multiple paraspinal dentate shaped extensions (Christmas tree sign) over dorsolumbar region while it disappeared in subsequent images after mobilization of patient. There was also appearance tracer in both kidneys and urinary bladder within 1 hour after injection (Figure 1). Basal cistern was visualized at 2 hour followed by visualization of lateral ventricles and persistent renal activity (Figure 2). Eighteen hour images showed no activity over cerebral hemisphere but persistent activity over spinal canal, basal cistern, lateral ventricles and visualization of Sylvain fissure and kidneys (Figure 3). On the basis of these scintgraphic findings diagnosis of communicating hydrocephalus with spinal leak due to raised intraspinal CSF pressure secondary to tuberculous meningitis/arachnoiditis was made. Ventriculo-peritoneal (VP) shunt was placed to reduce raised intracranial pressure. MRI brain was also performed which revealed a small tuberculoma in right cerebellar region which further strengthen the diagnosis of tuberculosis. Patient was discharged on anti-tuberculosis medications with significant improvement in symptoms.

\section{Discussion}

Radionuclide cisternography (RC) is an underutilized but sensitive modality used to differentiate between normal pressure and noncommunicating hydrocephalus $[1,2]$. It can also detect spinal CSF

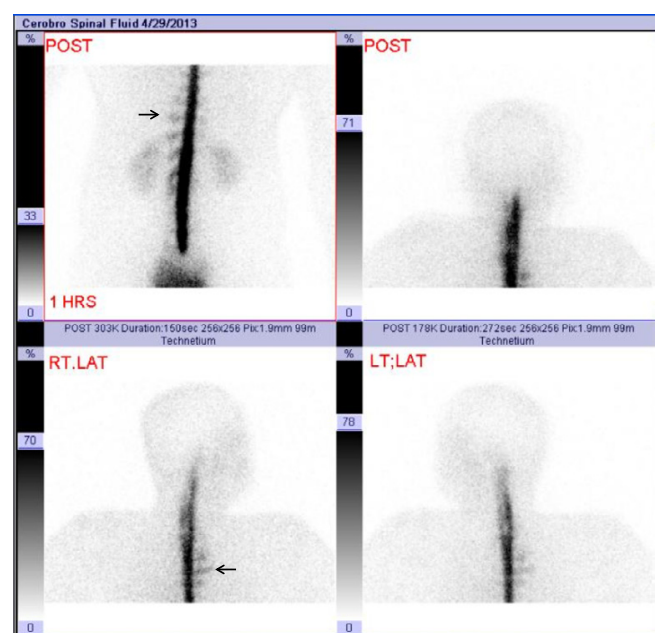

Figure 1: Radionuclide cisternography 1 hour static images showing dense intrathecal spinal activity with dentate shaped paraspinal extension (Christmas Tree Sign) (arrows) with appearance of activity in kidneys and urinary bladder.

leakage [3]. In this case RC showed a communicating hydrocephalus with evidence of CSF leak from paraspinal spaces into systemic circulation depicted as "Christmas Tree Sign" [4]. This characteristic sign was appreciable while patient remained supine for 2 hours and disappeared in subsequent images acquired after erect posture, providing a direct evidence [5] of CSF leak. This was supported by indirect evidences of CSF leak like early visualization of kidneys and urinary bladder within 1 hour [5] and absent cerebral activity till 18

*Corresponding author: Maseeh uz Zaman, Associate Professor and Section Head Nuclear Medicine, Department of Radiology; Aga Khan University Hospital (AKUH), Karachi, Pakistan, E-mail: maseeh.uzzaman@aku.edu

Received June 22, 2013; Accepted August 08, 2013; Published August 12, 2013

Citation: Fatima N, Zaman Mu, Aleem Bhatti Au, Khurshaidi IH, Siddiqui AJ, et al. (2013) Christmas Tree Sign: Paraspinal Cerebrospinal Leak on 99mtc-DTPA Radionuclide Cisternography. J Nucl Med Radiat Ther 4: 160. doi:10.4172/21559619.1000160

Copyright: ( 2013 Fatima N, et al. This is an open-access article distributed under the terms of the Creative Commons Attribution License, which permits unrestricted use, distribution, and reproduction in any medium, provided the original author and source are credited. 
Citation: Fatima N, Zaman Mu, Aleem Bhatti Au, Khurshaidi IH, Siddiqui AJ, et al. (2013) Christmas Tree Sign: Paraspinal Cerebrospinal Leak on 99mtc-DTPA Radionuclide Cisternography. J Nucl Med Radiat Ther 4: 160. doi:10.4172/2155-9619.1000160

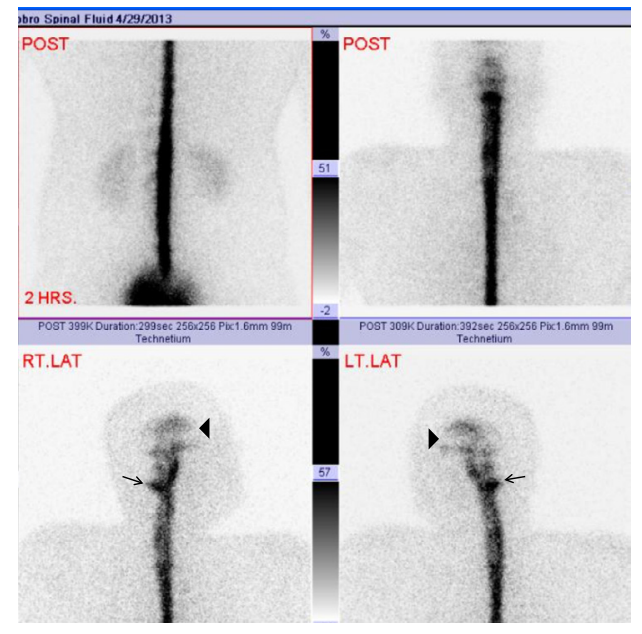

Figure 2: Radionuclide cisternography 2 hour static images showing appearance of basal cistern (arrow) and lateral ventricles (arrow head) with disappearance of Christmas Tree Sign as images were acquired after mobilization of patient.

hour after radiotracer injection. This early visualization of renal activity could be explained by leak of tracer from CSF space into systemic circulation followed by excretion through kidneys into urinary bladder.

We conclude that RC is a safe, sensitive and reliable modality for differentiating various types of hydrocephalus and Christmas Tree Sign and early appearance of renal activity are good predictors of CSF leak into systemic circulation.

\section{References}

1. Sandra KL, Dominique D, Leon P, Martin PS (2003) Cerebrospinal fluid imaging. $\left(4^{\text {th }}\right.$ edn), Philadelphia, Lippincott Willims \& Wilkins $835-848$.

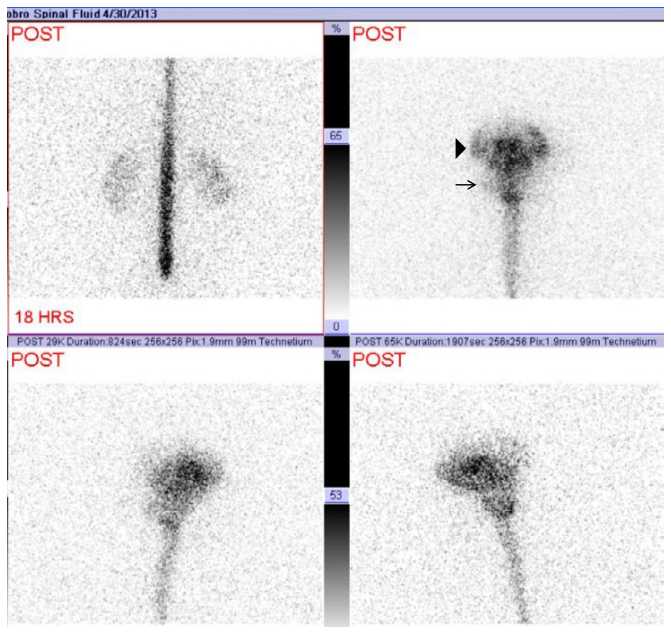

Figure 3: Radionuclide cisternography 18 hour static images no activity over cerebral hemisphere, visualization of Sylvian fissure (arrow head) with persistent activity over spinal canal, basal cistern (arrow), lateral ventricles and kidneys.

2. Schievink WI, Maya MM, Louy C, Moser FG, Sloninsky L (2013) Spontaneous intracranial hypotension in childhood and adolescence. J Pediatr 163: 504-510.

3. Reyhan M, Aydin M, Sukan A, Yapar AF, Karakurum B (2005) Radionuclide cisternography in cerebrospinal fluid leak: Christmas tree or railroad pattern. Turk J Nucl Med 14: 63-64

4. Del Mastro C, Cicone F, D'Andrea G, Scopinaro F (2009) Tc-99m DTPA cisternography shows disappearance of cerebrospinal fluid leakage after standing a short time. Clin Nucl Med 34: 29-30.

5. Takahashi M, Momose T, Kameyama M, Mizuno S, Kumakura Y, et al. (2005) Detection of cerebrospinal fluid leakage in intracranial hypotension with radionuclide cisternography and blood activity monitoring. Ann Nucl Med 19 339-343. 